\title{
Vegetales Subterráneos: Practicas Seguras para Consumidores $^{1}$
}

Amy Simonne $e^{2}$

Los vegetales subterráneos son crecidos bajo tierra. Ellos son expuestos a los microorganismos que se encuentra en la tierra. ¿Usted sabia que el producto fresco puede causar intoxicación alimenticia si no es manejado apropiadamente? En particular esto es cierto durante los meses de verano cuando el riesgo de la intoxicación alimenticia incrementa. Aquí están los pasos que usted puede seguir para reducir el riesgo de intoxicación alimentaria de estas deliciosas frutas.

\section{¿ Donde Hace Sus Compras:}

- Compre vegetales subterráneos que no este mallugados o dañados.

- Si compra vegetales de corte fresco, asegúrese que estén refrigerados o rodeados de hielo.

\section{En la Casa}

- Vegetales subterráneos fresco que necesitan refrigeración (zanahorias, remolacha) deben de ser refrigerados enseguida. Batatas o papas irlandesas no necesitan refrigeración.

- Todos los vegetales subterráneos deben de ser refrigerados dentro de dos horas de haber sido cortados o pelados.

- Deseche las sobras de los vegetales subterráneos después de dos horas de estar en la temperatura ambiente.

\section{Durante Preparación:}

- Lavarse las manos con jabón y agua tibia después y antes de:

$>$ El manejo del producto fresco

$>$ El manejo de carne cruda, aves caseras o mariscos

$>$ Usar el baño

$>$ Cambiar pañales

$>$ El manejo de animales

- Enjuague las verduras subterráneas con agua fría antes de comer. No use jabón o detergentes.

- Restriegue el producto subterráneo como las papas y zanahorias, con un cepillo limpio. Enjuague con agua fría.

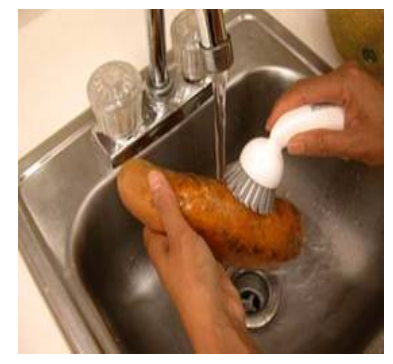

1. $\quad$ Este documento, FCS8746-Span, es uno de una serie del Departamento de Ciencias de la Familia, Juventud y Comunidad, del Servicio de Extensión Cooperativa de Florida, Instituto de Alimentos y Ciencias Agrícolas, Universidad de Florida. Fecha de publicación: Noviembre 2002. Revisado: Marzo 2006. Traducido Junio 2007 al español por Marcela Lacayo y Samara Vasquez. Favor de visitar el EDIS en el http://edis.ifas.ufl.edu

2. Amy Simonne, Ph.D., Profesora Asociada, Departamento de Ciencias de la Familia, Juventud y Comunidad, Instituto de Alimentos y Ciencias Agrícola, Universidad de Florida, 32611.

El Instituto de Alimentos y Ciencias Agrícolas es un empleador que provee Oportunidades Igualitarias, autorizado a proveer investigación, información educativa y otros servicios, únicamente a los individuos e instituciones que operan sin discriminación alguna con relación al credo, color, religión, edad, incapacidad, sexo, orientación sexual, estado civil, nacionalidad, opinion política o afiliaciones. Para más información sobre como obtener otras publicaciones de extensión, comuníquese con la oficina de Servicio de Extensión de su condado. Servicio de Extensión de la Florida / Instituto de Alimentos y Ciencias Agrícolas / Universidad de la Florida / Larry Arrington, Decano. 
- Ponga atención a los vegetales subterráneos que son consumidos crudos.

- Corte las áreas que están mallugadas o dañadas antes de preparar o comer.

- Lave tabla de cortar, platos, utensilio y la cima a menudo. Utilice agua tibia con jabón y enjuague bien. Desinféctelos después de ser usado con algún producto fresco, carne cruda, aves caseras o mariscos (mire la casilla).

- Desinfecte el área de lavaplatos con frecuencia para reducir la acumulación de microbios.

- ¡No cruce contamine! Utilice tabla de cortar e utensilios que estén limpios para el producto fresco. No combine los vegetales subterráneos que no han sido lavados con otras frutas o vegetales que estén limpios.

- Si puede, utilice diferentes tablas de cortar para carne cruda, aves caseras o mariscos.

- No consuma el hielo que ha estado en contacto con el producto fresco u otros productos crudos.

- Utilice una hielera con hielo cuando usted toma alimento perecedero fuera. Esto incluye vegetales y corte de frutas frescas.

Las cimas pueden ser desinfectadas usando la solución anterior. Spray desinfectantes y toallitas de limpiar funcionan como medida adicional de seguridad.

\section{Para desinfectar tabla de cortar, platos y utensilios:}

Mezcle una cucharada de cloro en un cuarto de agua

Vierta la mezcla en la superficie o sumerja los artículos en la solución y déjelo allí dentro por lo menos un minuto

Enjuague con agua caliente

Las cimas pueden ser desinfectadas usando la solución anterior. Spray desinfectantes y toallitas de limpiar funcionan como medida adicional de seguridad..

Siguiendo estos pasos reduce el riesgo de la intoxicación alimenticia que son causados por productos frescos.

\section{Para Más Información:}

Visite la página Web de Food and Drug Administration (FDA): http://www.fda.gov o llame FDA Indagaciones de Consumo al 1-888-SAFEFOOD (número de llamada gratuita). 